\title{
Software for enhancing accessibility and fighting info-exclusion
}

\author{
João Barroso • Frode Eika Sandnes • \\ Hugo Paredes • Leontios Hadjileontiadis • \\ Paulo Martins
}

Published online: 20 June 2014

(C) Springer-Verlag Berlin Heidelberg 2014

In the innovative world of Information and Communication Technologies (ICT), there is a continual flow of new information and experiences engaging individuals in the digital era. The use of ICT is increasing and proving to be of greater importance in people's everyday lives, accessing services to fulfill basic human needs. However, this increase in use and importance of ICT raises concerns to whether these technologies are fully accessible for all people, especially to disabled and elderly people. Disability can take many forms and can cover a wide range of impairments-some people have sensory disabilities covering difficulties with hearing, speech and sight; others are physically disabled and have problems with mobility; some suffer from cognitive impairments such as dyslexia and learning difficulties and there are those who battle with the debilitating effects of diseases such as arthritis and multiple sclerosis. Millions of people have disabilities that affect their use of the ICT due to the accessibility barriers that make it difficult or impossible for many people with disabilities to use them. Designing products that can be used by people with a wide range of abilities and disabilities, is a requirement in the years to come. A paradigmatic change

\author{
J. Barroso $(\bowtie) \cdot$ H. Paredes $\cdot$ P. Martins \\ INESC TEC, Porto, Portugal \\ e-mail: jbarroso@utad.pt \\ J. Barroso $\cdot$ H. Paredes $\cdot$ P. Martins \\ Universidade de Trás-os-Montes e Alto Douro, Vila Real, \\ Portugal \\ F. E. Sandnes \\ Oslo and Akershus University College of Applied Sciences, \\ Oslo, Norway \\ L. Hadjileontiadis \\ Aristotle University of Thessaloniki, Thessaloníki, Greece
}

in the software industry is needed to focus on the benefits of universal design. In fact, there is an increasing recognition that ICT accessibility can be a tool for commercial growth and the promotion of anti-discrimination legislation. Access to technology by disabled and elderly people is a major issue in allowing their integration in society. The growing global proportion of disabled and elderly people signifies that the urgency of this issue will not decrease in the years to come.

This special issue comes after the successful organization of the 4th International Conference on Software Development for Enhancing Accessibility and Fighting Info-exclusion-DSAI 2012, which was held in Douro Region, Portugal (http://dsai2012.utad.pt/). This UAIS special issue is focused on research related to interfaces and interaction, assistive technologies, case studies and aging, taking also into account the target audience of the UAIS Journal. As a result, six (6) papers describing methodologies, systems, case studies and literature reviews from the area of universal access comprise the special issue.

Márcio Martins, António Cunha and Leonel Morgado's "Usability test of 3D connection 3D mice versus keyboard+mouse in Second Life undertaken by people with motor disabilities due to medullary lesions" evaluates the usability of 3D controllers to navigate in 3D virtual worlds. The usability test was performed by 10 participants with motor disabilities due to medullary lesions on C5-D11 vertebrae. The main conclusion is that the most challenging tasks in the keyboard+mouse combination become less challenging using 3D mice and the least stable mouse, SpaceNavigator, originated the best feedback, contrary to originally expected results.

The contribution by Margaretha Izzo, entitled "Universal Design for Learning: Enhancing Achievement of 
Students with Disabilities" defines Universal Design for Learning (UDL) and presents examples of how universally designed technology hardware and software applications benefit students with disabilities who are majoring in science, technology, engineering or mathematics majors. The results show that UDL strategies enhance learning for all students, including students with disabilities who are majoring in STEM.

In their paper, "Learning substraction and addition through digital boards: a Down syndrome' case", Carina González et al. examine key issues involving the interaction, design and usability of a digital whiteboard interface to support Down syndrome (DS) students in their learning. The authors present the main strategies, procedures and errors of DS students for carrying out addition and subtraction algorithms that are more predominant in the DS population. The results reveal the importance of visual aids in teaching to individuals with DS and the advantages of using the whiteboard for students who have difficulty writing.

María González, Lourdes Moreno and Paloma Martínez in their paper "Approach design of an accessible media player" discuss the access to rich and interactive content on the web and the required media alternative required for users' special needs. The authors present an approach with accessibility requirements following standards to include accessibility in a user agent for delivering accessible multimedia content based on it and a conceptualization of these requirements that provides an abstract user interface which may be integrated into the development process. The study is complemented by a usability check to the presented mechanisms and the lessons learned.

In the paper by Alexandra Queirós et al., "Usability, Accessibility and Ambient Assisted Living: a Systematic Literature Review", a systematic literature review of the AAL technologies, products and services is presented. The authors aim to establish the current position regarding user interaction and how end-users are involved in the AAL development and evaluation processes. The results show the need to improve the integration and interoperability of the existing technologies and to promote user-centric developments with a strong involvement of end-users, namely in what concerns usability and accessibility issues.

The paper "Indoor localization and navigation for blind persons using visual landmarks and a GIS" by Miguel Serão et al. presents a system which integrates a geographic information system of a building with computer vision. The system aims to improve the autonomy of persons with very low vision during indoor navigation.

In conclusion, this special issue presents several perspectives to provide access to ICT to people with disabilities and to the elderly. The contributions share a common need to understand users' interaction requirements and the development of solutions that can fulfill their needs and expectations. The importance of setting up standards and guidelines for developing accessible software solutions is also evident in the contributions of this special issue. These are common concerns, which the guest editors have tried to highlight with the selection of the papers included in this special issue.

The guest editors would like to thank all the reviewers for their valuable input, as well as the authors, who at all times pursued the best quality. Special thanks to Constantine Stephanidis, the Editor-in-Chief of the Universal Access in the Information Society, international journal, for his guidance and all the help during the preparation of this issue. It is hoped that the readers of the UAIS Journal will find the papers of this special issue interesting.

The Guest Editors,

João Barroso, Frode Eika Sandnes, Hugo Paredes, Leontios Hadjileontiadis and Paulo Martins

\section{List of reviewers}

António Teixeira-DETI/IEETA, Universidade de Aveiro, Portugal

António Pereira-Polytechnic Institute of Leiria, Portugal Bernhard Stoger-University of Linz, Austria

Cecilia Sik Lanyi-University of Pannonia, Hungary

Christian Liesen-University of Applied Sciences of Special Needs Education, Switzerland

Enrico Pontelli-New Mexico State University, United States

Esmond Walshe-IBM, Ireland

Franz Puhretmair-Kompetenznetzwerk KI-I, Austria

Frode Eika Sandnes-Oslo and Akershus University, College of Applied Sciences, Norway

Grigori Evreinov-School of Information Sciences, University of Tampere, Finland

João Rodrigues-University of Algarve, Portugal

José Antonio Borges-Instituto Tércio Pacitti de Aplicações e Pesquisas Computacionais da UFRJ, Brazil

José Alves Diniz-Technical University of Lisbon, Portugal

José Luis Sevillano Ramos-Universidad de Sevilla, Spain Katsuhito Yamaguchi-Nihon University, Japan

Laura Burzagli-Institute of Applied Physics, National Research Council, Italy

Lenka Lhotska-Czech Technical University in Prague, Czech Republic

Leonel Morgado-Universidade Aberta, Portugal

Leontios Hadjileontiadis-Aristotle University of Thessaloniki, Greece

Manuel Cota-University of Vigo, Spain

Mariluz Guenaga-Deusto Foundation, Spain

Marlene Hilzensauer-University of Klagenfurt, Austria 
Petri Ronnholm-Aalto University, Finland

Pier Luigi Emiliani-National Research Council (CNR), Italy

Ramiro Gonçalves-INESC TEC and Universidade de Trás-os-Montes e Alto Douro, Portugal

Simone Bacellar Leal Ferreira-Universidade Federal do Estado do Rio de Janeiro, Brazil
Stavroula Ntoa-Foundation for Research and Technology-Hellas (FORTH), Greece

Vítor Filipe-INESC TEC and Universidade de Trás-osMontes e Alto Douro, Portugal

Willibald Kremser-Austrian Computer Society (OCG), Austria

Yehya Mohamad_Fraunhofer FIT, Germany 